\title{
HYDATID CYST CAUSING SPINAL COMPRESSION
}

\author{
By Sudha Suri, M.D., Inder Singh, M.D., D. R. Gulati, M.S., Dip. Neuro-Surgery \\ (McGill), M.A.M.S. and J. S. SoDHI, D.M.R.D., F.R.C.R., M.A.M.S. \\ Postgraduate Institute of Medical Education and Research, Chandigarh, India
}

\begin{abstract}
This report deals with two cases of spinal cord compression, one secondary to hydatid disease of $\mathrm{C}_{4}$ vertebra and the other due to a posterior mediastinal hydatid with an intraspinal component. After a brief review of the pertinent literature and pathogenesis of the disease, the distinguishing radiological features have been brought out.
\end{abstract}

Key words: Echinococcosis; hydatidosis spine; spinal echinococcosis; spinal compression; mediastinal echinococcosis.

SPINAL cord compression is one of the most unusual presentations of hydatid disease. This may be the result of extension of a hydatid cyst which is primarily involving the vertebra (Balasubramanium, 1972) or is mainly located in the extradural space (Chitkara, I957). Sometimes it is caused by a subdural spinal hydatid cyst which is compressing the spinal cord directly (Das, I957). Rarely it may follow a mediastinal hydatid cyst which is having an intraspinal extension (Rakower, I960). We came across two cases of spinal cord compression secondary to hydatid disease. In the first case, the patient presented with paraplegia which was due to the intraspinal extension of a primary mediastinal hydatid cyst. In the second case, the patient developed tetraplegia as a result of vertebral hydatid involving the $\mathrm{C}_{4}$ vertebra.

The aim of this presentation is to report our experience with these two cases and to emphasise that preoperative diagnosis of the condition though difficult is extremely important from the management point of view. A properly planned surgical approach will help to prevent recurrence due to contamination of the exposed tissues by the live scolices in the hydatid fluid.

\section{Case Reports}

Case I. S. D., a 28-year-old female, presented with paralysis of both lower limbs and retention of urine of one and a half months' duration. On physical examination, the positive findings included a mild kyphosis and tenderness at Th9-ro level, complete anaesthesia up to Thy level and flaccid paraplegia with retention, overflow of urine. A clinical diagnosis of spinal cord compression of extradural nature at the level of Th6-7 was made and the patient was further investigated. A routine chest X-ray revealed a rounded opacity in the right cardiophrenic angle. X-rays of the dorsal spine (Fig. I) showed the pressure erosion of the Th8 and Thy vertebral body on the right side with widening of the 9 th intercostal space. The intervertebral disc spaces were normal. A myelogram was then carried out. The contrast was introduced by the cisternal route. There was a complete block of extradural nature at the level of Th8 vertebra. The spinal cord along with the theca was pushed towards the left side (Fig. 2). The lateral view revealed the erosion of the posterior surface of the body of Thy vertebra with widening of the intervertebral foramen at that level (Fig. 3). With these findings, a radiological diagnosis of a space-occupying lesion of the posterior mediastinum with an intraspinal extension was made and dumb-bell neurofibroma was suspected. The patient underwent laminectomy of 8 th to Ioth thoracic vertebrae. The lesion was found to be a dumb-bell type of 
hydatid cyst which had both intraspinal and extraspinal components at the level of Th9. Pathology examination confirmed the diagnosis of Taenia echinococcus. The cyst was removed in toto. The patient, however, showed no improvement in the neurological status at the time of discharge 3 weeks after operation.

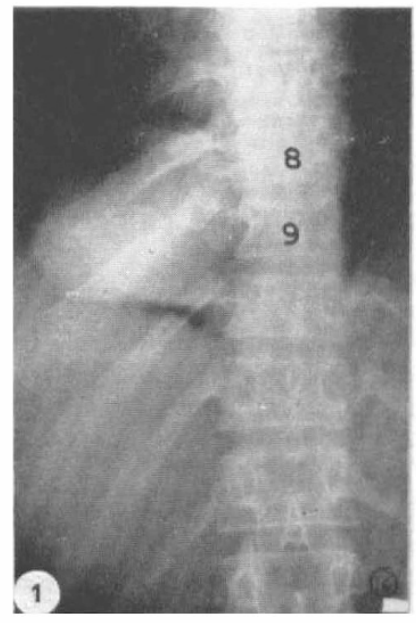

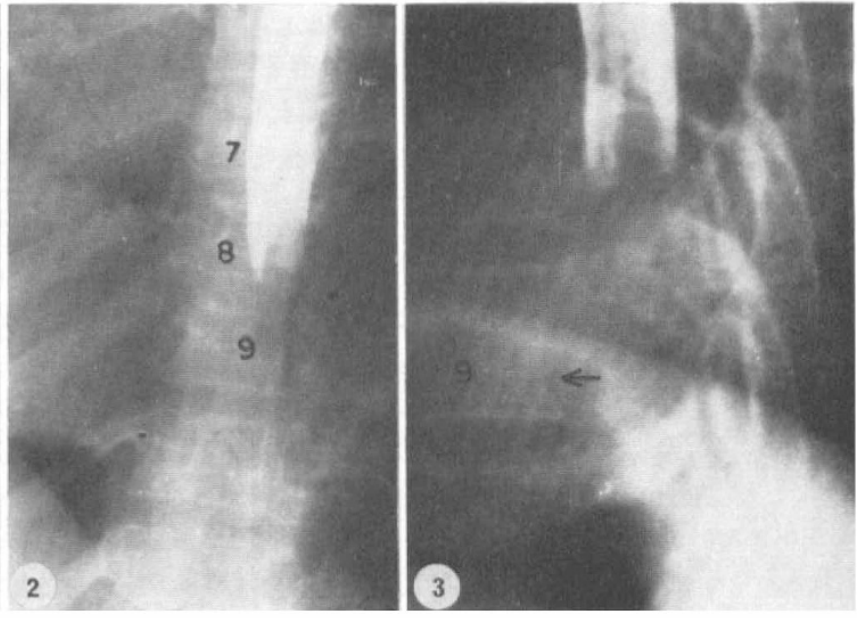

FIG. I (Case I):

A rounded opacity is seen in the right cardiophrenic angle with pressure erosion of Th9 vertebral body on its right side.

FIG. 2 (Case I):

Myelogram done by cisternal route revealed a complete extradural block at Thy level. The cord along with theca has been pushed to the left side.

FIg. 3 (Case I):

Myelogram, lateral view. In addition to the extradural block, the pressure erosion of the posterior surface of Thy vertebra and widening of intervertebral foramen at this level is seen $(\leftarrow)$.

Case 2. K. D., a 26-year-old male, noticed a swelling in the nape of the neck ro years ago which was partially excised in another hospital. Three years prior to present admission, the swelling reappeared in the same location and he developed progressive weakness of upper and lower extremities with difficulty in micturition. On examination, there was a large $(8 \times 10 \mathrm{~cm})$, tense swelling in the nape of the neck extending from Ist to 5 th cervical vertebra. Neurological examination revealed grade II to grade III power in the left upper limb, grade III in the right upper limb and grade IV in the lower extremities. There was sensory loss to all sensations up to $\mathrm{C}_{4}$ dermatome. The deep tendon reflexes were exaggerated in the upper as well as lower extremities. The tone was increased in all four limbs and both plantars were extensors.

$\mathrm{X}$-ray of the cervical spine revealed cystic appearance and collapse of $\mathrm{C}_{4}$ vertebral body, with scalloping of the posterior surface of $\mathrm{C}_{3}$ vertebra. There was marked decalcification of laminae and spinous processes of $\mathrm{C}_{3}$ and $\mathrm{C}_{4}$ vertebrae with narrowing of the $\mathrm{C}_{3}-4$ disc space (Fig. 4). The clinical impression was: Cervical neurofibroma with cervical cord compression? Sarcoma? Caries spine?

The patient was operated upon and a multiloculated lump was seen. Inadvertent opening into one of the loculi resulted in escape of clear hydatid fluid and numerous daughter cysts. The cyst was separated from surrounding structures and removed in toto. The patient showed an excellent recovery with return of grade IV power in all the extremities. He was able to walk and use his hands adequately at the time of discharge. 

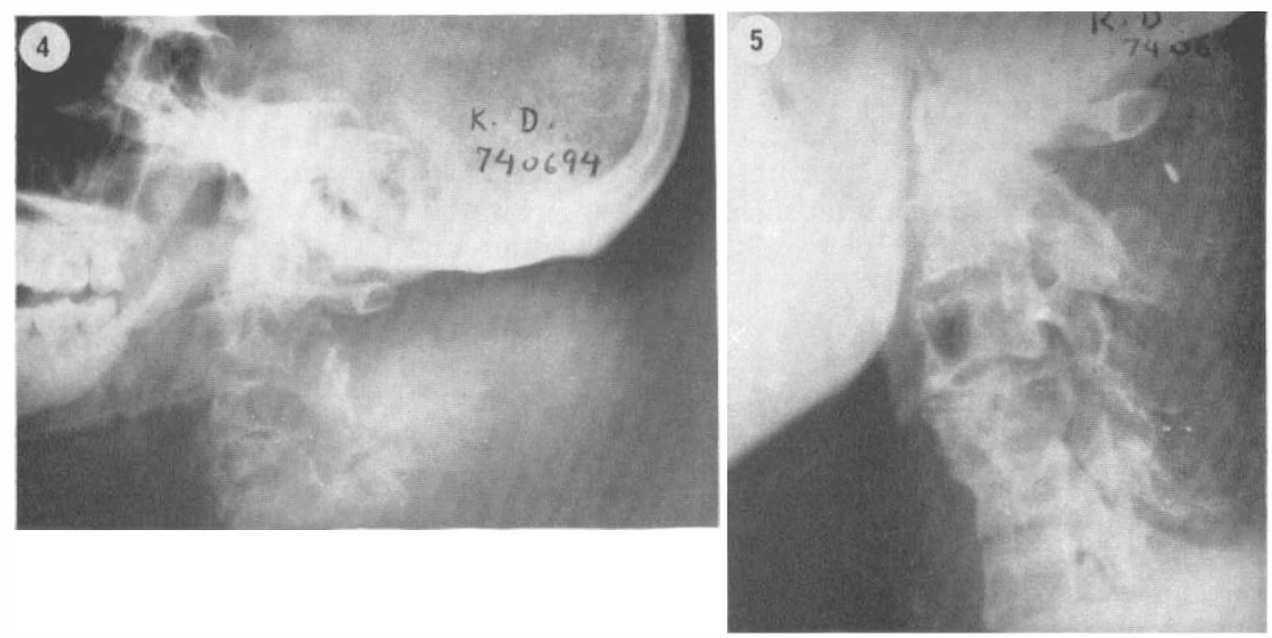

Fig. 4 (Case 2):

Lateral view of skull and upper cervical spine shows big soft tissue swelling at the nape of the neck. Cystic changes are seen involving the $\mathrm{C}_{4}$ vertebral body with scalloping of posterior surface of $\mathrm{C}_{3}$ and marked de-ossification of laminae and spinous processes of $\mathrm{C}_{3}$ and $\mathrm{C}_{4}$. The corresponding disc space is narrowed.

FIg. 5 (Case 2):

Lateral view C-spine (6 months' postoperative) shows re-ossification of $\mathrm{C} / 34$ vertebrae. $\mathrm{C}_{4}$ shows residual cystic changes.

\section{Discussion}

Involvement of the mediastinum or the vertebra in hydatid disease is considered to be extremely rare. Incidence of mediastinal hydatid is described to be o- 6 per cent in the various series (Rakower, 1960). The reported incidence of skeletal involvement is 0.28-3.I per cent (Rayport, I964). Spine is affected in 50 per cent of the cases, the order of involvement being dorsal, lumbar, sacral and cervical in descending frequency (Robinson, I960).

Pathogenesis: The echinococcus larvae having gained access to the human intestine through ingestion of contaminated food and water pass through the intestinal wall into the portal circulation. Most of them settle in liver ( 70 per cent) while others ( 15 per cent) implant in the lungs. The remaining I 5 per cent succeed in bypassing the hepatic and lung barrier and reach the systemic circulation. These then implant in any organ of the body, e.g. bone, spleen, kidney, heart and cerebrum or anywhere. Sometimes these organs are affected without any involvement of the liver or the lungs. This was explained by Perosio (1963), who suggested that larvae could travel via intestinal lymphatics into the thoracic duct thus bypassing the liver.

The incidence of paraplegia in vertebral hydatid varies from $25-50$ per cent (Vengsarkar, 1965). The echinococcus larvae settle in the bone marrow and start producing multimicrovesicular type of cysts. There is no ectocyst formation due to minimal tissue reaction. The original focus is in the body of the vertebra but later on the appendages may also be involved. 
Radiologically, the changes are represented as small multiple cystic lesions having a soap-bubble appearance affecting the vertebral body alone or along with the pedicles and laminae. When the cysts break into paravertebral tissues, a paravertebral shadow results due to the formation of hydatid abscess. This may show calcification. At this stage, differentiation from tuberculosis is at times very difficult as the clinical picture resembles the latter very much. Changes in the intervertebral disc. space are controversial. Vengsarkar et al., while reviewing the hydatid disease of the spine in 1965 , found that intervertebral disc space was always spared in their cases and they thought this to be a characteristic feature of the disease. Contrary to this, Mills in 1956 had reported that the articular cartilage does not offer much resistance and intervertebral discs, although more resistant, are also invaded and allow spread of the disease to the adjacent vertebrae. Findings of our case also support his observations. When the disease extends posteriorly into the extradural space, paraplegia results due to pressure on the spinal cord. This manifests radiologically as an extradural block on myelography.

The mediastinal hydatid may arise as a primary focus in the mediastinum or it may follow as an extension of the costal, vertebral or pulmonary hydatid disease. The latter is more frequent. The commonest site is the posterior mediastinum, although anterior and middle mediastinum may also be affected (Rakower, I960). The cyst appears as a rounded opacity in the paravertebral gutter. There may be erosion of the body, the pedicle or the transverse processes of the vertebrae and widening of the corresponding intercostal spaces. The changes very much resemble the neurogenic tumours and in fact radiological differentiation may at times be impossible, particularly when there is intraspinal extension of the cyst. The paravertebral hydatids are known to grow in an hour-glass fashion thus simulating a dumb-bell type of neurofibroma. There is widening of the intervertebral foramen and erosion of the posterior surface of vertebral body just as in Case No. 2. Thus the oftenmade statement that the tumours of the paravertebral gutter are neurogenic unless proven otherwise does not hold true. A preoperative diagnosis of this condition is possible only if a mediastinal hydatid disease is considered in the differential diagnosis of every mediastinal mass, particularly in countries where the disease is endemic.

\section{SUMMARY}

Two cases of spinal cord compression due to hydatid disease of the spine and the mediastinum are reported. The pathogenesis of primary mediastinal and vertebral echinococcosis has been discussed with review of the pertinent literature. The various radiological features helpful in the diagnosis have been emphasised.

\section{RÉSUMÉ}

Deux cas de compression du cordon médullaire causés par la maladie Hydatique de la colonne vertébrale et du médiastin ont, été signalés. La pathogénic de l'échinococcose primaire du médiastinal et du vertebrale a été discuter avec un revue littérature convenable. Les caractéristique radiologiques qu'aident le diagnostic ont été accentués.

\section{ZUSAMMENFASSUNG}

Zwei Fälle von Rückenmarks Kompression als Folge von hydatid Krankheit der Wirbelsäule und des Septummediastinale werden berichtet. Die Pathogenese der primären mediastinalen und vertebralen Echinococosis ist diskutiert im Lichte der Literatur. Die verschiedenen radiologischen Merkmale, bei bie der Diagnose behilflich sind, werden hervorgehoben. 


\section{REFERENCES}

Balasubramanium, V., Ramanujan, P. B. \& Ramamurthi, B. (1970). Hydatid disease of the nervous system. Neurology India, 18, Supplement (I), 92-95.

Chitkara, N. L. (1957). Hydatid cyst as a cause of paraplegia. F. Indian Medical Association, 28, 520 .

DAs, P. (1957). Subdural spinal hydatid. Indian F. of Surgery, 19, 349.

Mills, T. J. (1956). Paraplegia due to hydatid disease. F. Bone foint Surg., 38B, 884-89i. Perosio, A. (1963). Hidatidosis cardiomediastinica. Prensa, Med. Argen, 10, 669 (French), RAkower, J. \& Milwidsky, H. (I960). Primary mediastinal echinococcosis. Am. $f$. Medicine, 29, 73-83.

RAYPORT, M., WisOFF, H. S. \& Zaiman, H. (1964). Vertebral echinococcosis. F. Neurosurgery, 2I, 647-59.

Robinson, R. G. (I960). Hydatid disease of the spine and its neurological complications. Brit. F. Surgery, 47, 30I-306.

Vengsarkar, U. S. \& Abraham, J. (1965). Hydatid disease of the spine. F. Post Graduate Medicine, II, I33-136.

\section{NOTE ADDED IN PROOF}

The X-ray of the cervical spine taken 6 months postoperatively (Fig. 5) showed considerable re-ossification of the $\mathrm{C} / 34$ vertebrae. Cystic changes in the $\mathrm{C}_{4}$ vertebral body, however, persisted. 